\title{
Editorial
}

\author{
André Rangel \\ CITAR \\ Catholic University, Portugal \\ a@3kta.net
}

\section{Miguel Carvalhais}

Faculty of Fine Arts

University of Porto, Portugal

mcarvalhais@fba.up.pt

\author{
Luísa Ribas \\ Faculty of Fine Arts \\ University of Lisbon, Portugal \\ I.ribas@belasartes.ulisboa.pt
}

\author{
Mario Verdicchio \\ School of Engineering \\ University of Bergamo, Italy \\ mario.verdicchio@unibg.it
}

This special issue of the Journal of Science and Technology of the Arts (CITARJ) is dedicated to the 2018 edition of the xCoAx conference on Computation, Communication, Aesthetics and $\mathrm{X}$, which took place in Madrid, Spain, from July $11^{\text {th }}$ to July $13^{\text {th }}$.

For the first time, $x$ CoAx was not hosted in a country of one of the members of the Organising Committee, which means that our usual adventure of last minute fixes of technical gear, rushes to the grocery store to buy missing cups for the coffee breaks, hotel reservations for the keynote speakers etc. happened in foreign territory. This could have added to the stress of organising and managing a multifaceted event like $\mathrm{xCoAx}$, but it was actually made easier by our gracious hosts at the Superior Technical School of Architecture of the University of Madrid and at the Centro Arte Complutense, to whom we will always be very grateful.

2018 has been a very intense year, to say the least. So much has happened and so much is still happening all over the world that being overwhelmed by the news has become a daily routine for many of us. Maybe this is why we cannot help looking at this year's papers through something like a journalistic lens that compels us to make some loose yet perhaps significant analogies between what these scholars have written and what is going on in the world today. Since apparently there is already too much bias in online and offline content everywhere, we will let our readers enjoy the papers in this issue freely, and maybe come up with some analogy on their own.

As in the previous occasions that the Editorial Board of CITARJ has given us this great opportunity, we invited the authors of some of the best papers that were presented at $\mathrm{xCoAx}$ to write new articles that would allow them to explore in further depth the topics that they have presented at the conference. This is how we obtained this interesting selection of works, which cover an unprecedentedly wide range of topics.

Lautenschlaeger articulates a discourse on the creation of media artworks based on the translation between different media that kicks off from a sensorial absence. Presence, on the contrary, is the concept around which Nake builds an analysis that is historical but accompanies us up to the latest results of Artificial Intelligence applied to Art, observed from the perspective of what is in flux and what is constant. Ludovico is also on a journey in time, showing us how technology has changed the physicality of publications through digitization, at the same time minimizing material spaces and maximizing conceptual ones. 
Speaking of journeys, Flisykowska takes us on the most ambitious of them all, to Mars, where she illustrates how 3D printing can create artefacts that embody speculative design based on astrophysics and biology. The last two papers bring us back to Earth with a thud. Hernández-Ramírez warns us that a lot, maybe too much has been said and written about design, and proposes a very intriguing, and perhaps head-scratching for some, conceptual framework to keep the discourse in check and focus only on significant contributions. Finally, Costa reminds us that, despite appearances, technology is not neutral, and it comes with several kinds of biases, among which he focuses on the gender issues of the latest Al-driven assistants.

All these works show that scholarly and artistic activities do not belong in an ivory tower, but are always projected towards the most compelling issues and problems we see all around us. In a very, very complex world like ours, maybe this is exactly what we need. Here's to a better future.

\section{BIOGRAPHICAL INFORMATION}

André Rangel, 1971. Intermedia artist-cum-designer that holds a PhD in Science and Technology of the Arts, a Master in Digital Arts and a Degree in Communication Design. Currently Assistant Professor at the Faculty of Fine Arts of the University of Porto and Researcher at the Research Center for Science and Technology of the Arts. $3 \mathrm{kta}$.net founder and director, xCoAx.org co-founder and co-organizer.
Luísa Ribas holds a PhD in Art \& Design (2012), a Master in Multimedia Art and a Degree in Communication Design from the Faculty of Fine Arts, University of Porto. Her research addresses interactive systems as aesthetic artifacts, their design and experience, while focusing on soundimage relations. She has contributed to publications and events on digital art and design as a collaborator of ID+ and CIEBA research centers. As a professor at the Faculty of Fine-Arts, University of Lisbon, she teaches Communication Design with a focus on print and digital computational media.

Mario Verdicchio was born in Milano, Italy in 1975. $\mathrm{He}$ obtained a $\mathrm{PhD}$ in Information Engineering in 2004 at Politecnico di Milano, where he worked in the Artificial Intelligence and Robotics group. He cofounded xCoAx in 2012 while working as a researcher at the School of Engineering at the University of Bergamo, Italy. His collaborations include the University of Virginia, USA, the University of Porto, Portugal, and the University of the West of Scotland, UK.

Miguel Carvalhais is a designer and musician. He's an Assistant Professor at the Faculty of Fine Arts of the University of Porto, a researcher at INESC TEC and a fellow at V2_Lab for the Unstable Media. He's the author of "Artificial Aesthetics: Creative Practices in Computational Art and Design". 